\title{
Characterization of the Spatiotemporal Attributes of Sclerotinia Flower Blight Epidemics in a Perennial Pyrethrum Pathosystem
}

Sarah J. Pethybridge, Botanical Resources Australia-Agricultural Services Pty. Ltd., Ulverstone, Tasmania, 7315, Australia; Frank S. Hay, Tasmanian Institute of Agricultural Research (TIAR), University of Tasmania-Cradle Coast Campus, Burnie, Tasmania, 7320, Australia; and David H. Gent, United States Department of AgricultureAgricultural Research Service, Forage Seed and Cereal Research Unit, Oregon State University, Department of Botany and Plant Pathology, Corvallis 97331

\begin{abstract}
Pethybridge, S. J., Hay, F. S., and Gent, D. H. 2010. Characterization of the spatiotemporal attributes of Sclerotinia flower blight epidemics in a perennial pyrethrum pathosystem. Plant Dis. 94:1305-1313.

Sclerotinia flower blight, caused by Sclerotinia sclerotiorum, causes substantial losses in Australian pyrethrum fields. The spatiotemporal characteristics of epidemics were characterized in five fields over 3 years. Log likelihood tests indicated that the $\beta$-binomial distribution fit better than the binomial distribution for $92 \%$ of the data sets. The index of dispersion, $D$, was significantly greater than 1 in $97 \%$ of the data sets. The estimated parameters of the slope and intercept terms of the binary power law were 1.631 (standard error $[\mathrm{SE}]=0.059)$ and $0.678(\mathrm{SE}=0.099)$, indicating a high degree of aggregation at the individual sampling unit scale. In $69 \%$ of the data sets, the magnitude of the first-order autocorrelation coefficient $\hat{r}_{1}$, was significantly greater than 0 . In 11 of the 12 epidemics, the monomolecular model provided the best fit, indicative of monocyclic processes. A significant spatial association between apothecia and incidence of Sclerotinia flower blight within the lag of one sampling unit was also quantified. This study suggests that $S$. sclerotiorum apothecia emergence was closely synchronized with flower development, and epidemics were dominated by localized sources of ascosporic inoculums. This research provides the basis for improved management strategies for Sclerotinia flower blight in pyrethrum.
\end{abstract}

Pyrethrum (Tanacetum cinerariifolium (Trevir.) Sch. Bip.) is a perennial herbaceous member of the Asteraceae family. The commercial production of pyrethrum is for the extraction of the pyrethrins, which are contained within oil glands on the surface of the achenes of the flowers (10). These pyrethrins have unique insecticidal properties, which are becoming increasingly popular for pest control in both household and agricultural situations. These properties include rapid knock-down properties (3), ultraviolet light degradation which reduces the probability of persistence in the environment, and no evidence to date of resistance development within pest populations (31).

Corresponding author: S. J. Pethybridge E-mail: spethybridge@pyrethrum.com.au

The use of trade, firm, or corporation names in this publication is for the information and convenience of the reader. Such use does not constitute an official endorsement or approval by the United States Department of Agriculture or the Agricultural Research Service of any product or service to the exclusion of others that may be suitable.

Accepted for publication 22 June 2010.

doi:10.1094/PDIS-04-10-0311

(C) 2010 The American Phytopathological Society
Pyrethrum production in Australia currently supplies approximately $60 \%$ of the global market for pyrethrins. The production system is highly mechanized and involves field establishment in spring by precision seeding and, generally, four annual harvests thereafter, beginning in the following midsummer (3). Plants are semidormant each winter, followed by a synchronous flush of stems in spring. Stems reach maximum height (approximately $80 \mathrm{~cm}$ ) within 3 months of shoot emergence in spring and flowers form on the terminus of each stem branch (21).

Sclerotinia flower blight, caused by Sclerotinia sclerotiorum, is the dominant disease of pyrethrum flowers in Australia $(13,21)$. Botrytis flower blight, caused by Botrytis cinerea, can also infect pyrethrum flowers. The incidence and severity of Botrytis flower blight varies annually and is most often seen just prior to harvest and in windrows. The symptoms of the two diseases can be easily distinguished visually. Symptoms of Botrytis flower blight include fused disc florets and sporulation of $B$. cinerea. Early symptoms of Sclerotinia flower blight, caused by ascospores, are necrotic spots on the disc florets, which often occur in the ridge lines, followed by necroses of the entire peduncle extending into the stem approximately 1 to $2 \mathrm{~cm}$. Flowers affected by Sclerotinia blight typi- cally remain upright and the disc florets remain intact. In some cases, mycelia and sclerotia characteristic of $S$. sclerotiorum can be seen colonizing the diseased flowers in the field (Fig. 1). These flowers then shatter during the harvesting process and fall to the ground, causing direct losses in pyrethrin yield by reducing the number of harvestable flowers, although the magnitude of these losses have not yet been fully quantified. This process may also contribute to soilborne inoculum for crown rot and flower blight the following season. Plant losses due to crown rot can also be attributed to infection by $S$. minor $(13,18,21)$.

Management recommendations for flower diseases aim to control both Sclerotinia and Botrytis flower blights in concert. These include three to four fungicide applications at 10- to 14-day intervals, initiated when approximately $2 \%$ of the flowers have fully opened disc florets. The fungicides used within the management program are consistent across all fields, including alternate applications of tebuconazole and carbendazim $(18,21)$.

These management strategies translate into relatively extensive control efforts, particularly for the dominant disease, Sclerotinia flower blight. Remarkably, relatively little has been characterized with regards to the etiology and epidemiology of Sclerotinia flower blight in the unique, perennial production system of pyrethrum. The objective of this study was the generation of quantitative information on the spatiotemporal characteristics for Sclerotinia flower blight epidemics. This information is required for the determination of inferences on important epidemic information, including the relative contributions of local (within-field) and background (outside the field of interest) sources of inoculum, rates of epidemic development, and spatial characteristics of disease foci and any correlations with the occurrence of apothecia.

\section{MATERIALS AND METHODS}

Field sites and data collection. Sclerotinia flower blight epidemics in pyrethrum fields, herein referred to as fields $\mathrm{A}$ through F, in Tasmania, Australia, were assessed in the late spring and early sum- 
mer of 2007 (fields A and C), 2008 (field B), and 2009 (fields D, E, and F) from October to December. Both fields studied in 2007 were scheduled for first harvest. In 2009, two of the fields used in the study (D and E) were also approaching first harvest. All fields were located within a $45-\mathrm{km}$ radius of each other in north-central Tasmania. Fields contained either one of the two dominant cultivar types (proprietary) grown in this region and received standard agronomic inputs, such as disease and weed management practices, irrigation, and nutrient applications.

The incidence of Sclerotinia flower blight was assessed using a cluster sampling design. For each field, two rows (each $12.5 \mathrm{~m}$ long) were selected arbitrarily and marked for later identification and considered a transect. Along each 0.5-m section of the transects, five flowering stems were selected and all flowers on these stems were counted and assessed nondestructively for the presence or absence of symptoms (or signs) of Sclerotinia flower blight. A sampling unit consisted of all the flowers on each of the five
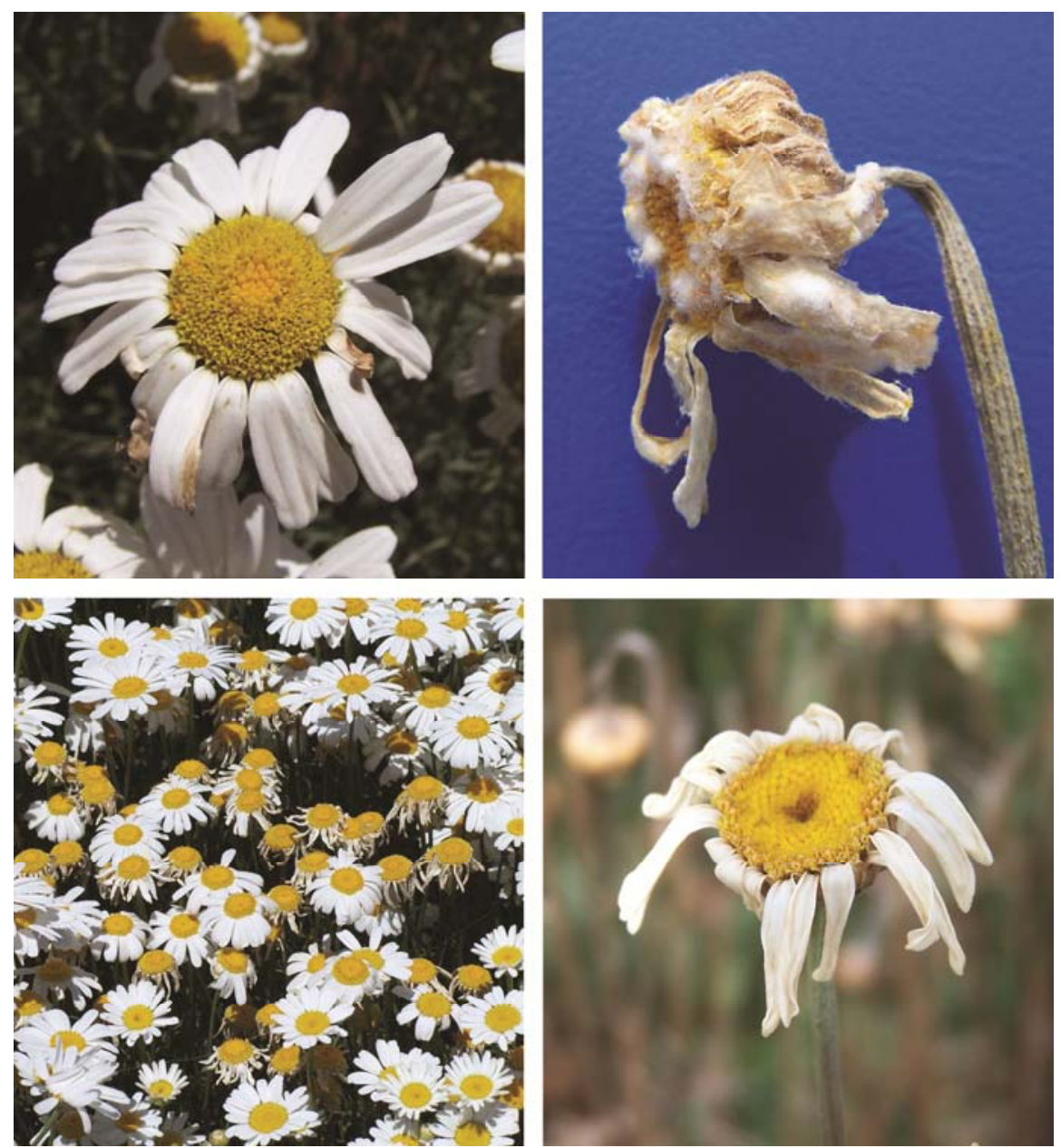

Fig. 1. Symptoms of Sclerotinia flower blight in pyrethrum. Top left: early symptoms of Sclerotinia flower blight (necrotic lesions on disc floret edges); top right: advanced Sclerotinia flower blight (floccose white mycelia, necrotic peduncle and weakened, necrotic stem); bottom left: small focus of Sclerotinia flower blight typical of the pattern of disease in the field; bottom right: further symptoms of Sclerotinia flower blight including necrotic, crinkled disc florets and a bleached or necrotic lesion extending down the stem with flower head remaining upright. soil surface was examined carefully for apothecia in each $0.5-\mathrm{m}$ section of each transect within the row where the sampling units were selected. In five of the six fields, two to three counts of apothecia also were made after harvest. The association between the number of apothecia per meter, incidence of diseased flowers, $\hat{p}$, and the number of days after the disease assessments were initiated (a measure of crop development) was quantified over all fields and sampling times by Spearman's rank correlation. Calculations were made in SigmaPlot (version 11; Systat Software, Inc.; San Jose, CA). Due to the relatively small number of plots where apothecia counts were made in a given transect, data from both transects in a given field were combined. Thus, there was a total of 32 data points for these correlation analyses.

Pathogen isolations and flower maturity. To confirm that disease symptoms were associated with $S$. sclerotiorum, samples of 20 diseased flowers were arbitrarily selected from fields A on 22 December 2007 and 17 December 2008, C on 20 December 2007, and E on 21 December 2009. Flowers were surface sterilized in $1 \%$ sodium hypochlorite for $2 \mathrm{~min}$, then rinsed three times in sterile, distilled water. Flowers were air dried in a laminar flow cabinet for a further $2 \mathrm{~h}$ and then placed on plastic mesh over damp tissue in sealed plastic trays. Five flowers were placed in each individual tray. Trays were incubated at room temperature $\left(10\right.$ to $15^{\circ} \mathrm{C}$, night, and 18 to $22^{\circ} \mathrm{C}$, day) before being assessed for the presence of characteristic white floccose mycelia or sclerotia of $S$. sclerotiorum after 15 to 20 days of incubation (29). The presence of other fungi, such as $B$. cinerea, the cause of Botrytis flower blight, was also recorded, if present. In addition, 300 arbitrarily selected flowers were also selected from each of the study areas in fields A $(1,10$, and 22 December 2007 and 3 and 18 November and 17 December 2008), C (28 November, 7, 12, 14, and 20 December 2007), and E (5, 14, and 21 December 2009) for assessment of flower maturity using the weighted mean average assessment technique (22).

Temporal analysis. Temporal disease progress was quantified in all epidemics occurring within the five fields using mean disease incidence. Linear, monomolecular, exponential, logistic, and Gompertz models were fitted to the temporal progress of disease incidence from assessments made between 15 October and 28 December within each year. Goodness-of-fit statistics examined to select the most suitable model for each dataset were (in order of preference) the $F$ statistic for linearity, the coefficient of determination $\left(R^{2}\right)$, the root mean square error, and a visual comparison of the residuals plotted against the predicted values $(19,20)$. Back-transformed coefficient of determination values were calcu- 
lated to obtain fitted disease incidence values to the original data (19).

Spatial analyses. Distributional analyses. The $\beta$-binomial and binomial distributions were fit to the incidence of diseased flowers using the computer program BBD (14). A good fit to the binomial distribution is an indication of a random pattern of diseased flowers, whereas a good fit to the $\beta$-binomial distribution is an indication of an aggregated pattern $(15,16)$. A loglikelihood ratio test statistic was calculated to determine whether the data were a better fit to the $\beta$-binomial or binomial distributions. The $C(\alpha)$ test was used to test whether aggregation in the distribution of diseased flowers could be described adequately by the $\beta$-binomial distribution.
Because $n$ varied among sampling units, it was not possible to calculate expected frequencies and associated $\chi^{2}$ goodness-offit tests for the distributions.

The degree of aggregation of disease incidence was quantified by the heterogeneity parameter, $\theta$, of the $\beta$-binomial distribution. This parameter provides a measure of variation in disease incidence per sampling unit $(15,16)$. The index of dispersion (D) was calculated by dividing the observed variance of diseased flowers $\left(v_{\mathrm{obs}}\right)$ by the theoretical variance for a binomial distribution $\left(v_{\mathrm{bin}}\right)$ where $v_{\mathrm{obs}}=$ $\left[\sum\left(x_{i}-\hat{p} n_{i}\right)^{2}\right] /(N-1)$ and $v_{\text {bin }}=n \hat{p}(1-\hat{p})$ and $x_{i}, \hat{p}, n$, and $N$ are as defined previously. When $\theta=0$ or $D=1$, the pattern of diseased flowers is random, with aggrega- tion indicated when $D>1$ or $\theta>0$. The degree of aggregation is directly proportional to the magnitude of the statistic. $D$ has a $\chi^{2}$ distribution, and can be used to test the null hypothesis of a random distribution of disease incidence with $N-1$ degrees of freedom (15).

Binary power law analyses. The binary power law expresses the relationship between the theoretical variance of binomial (random) pattern of disease incidence and an observed variance (12). When a large number of data sets are collected, the relationship between these variances provides a convenient method to characterize aggregation of disease incidence over multiple fields and time (16). The model was fitted to the observed and binomial vari-

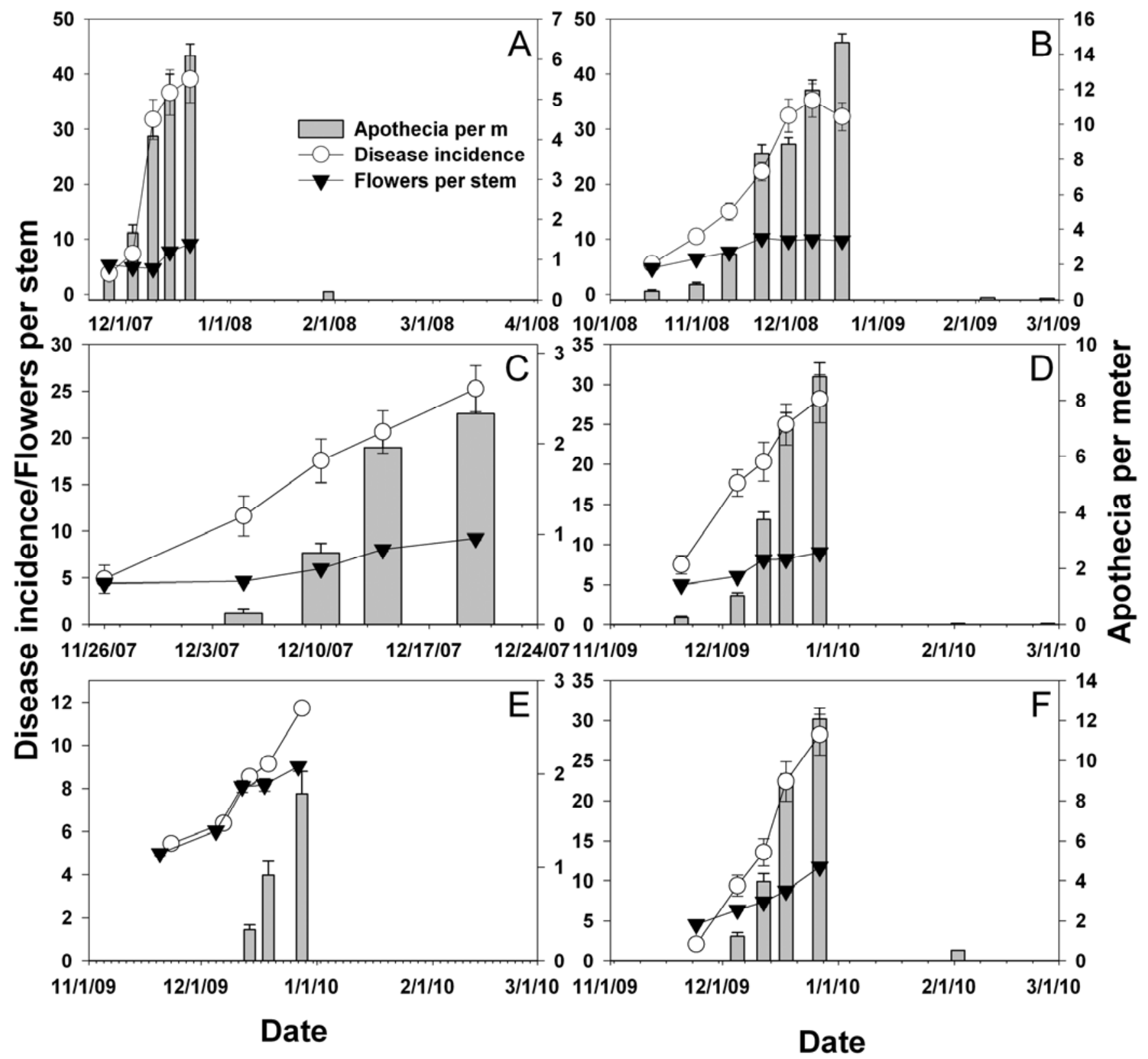

Fig. 2. Development of Sclerotinia flower blight on flowers and emergence of apothecia of Sclerotinia sclerotiorum in pyrethrum fields in Tasmania, Australia. The mean number of flowers per stem is provided as a reference for crop development. Data is presented for a field monitored in both A, 2007 and $\mathbf{B}$, 2008 and in four other fields monitored in C, 2007 or D-F, 2009. All fields except C were assessed on two or three dates after harvest (late December) for the presence of apothecia. 
ances through the log-transformed relationship:

$$
\ln \left(v_{\mathrm{obs}}\right)=\ln \left(A_{x}\right)+b \ln \left(v_{\text {bin }}\right)
$$

where $v_{\text {obs }}$ and $v_{\text {bin }}$ are as defined above. When $A_{x}=1$ and $b=1$, equation 1 indicates a random pattern of disease incidence that can be represented by the binomial distribution. When $A_{x}>1$ and $b=1$, disease incidence has an aggregated pattern that is not dependent on $p$; values of $b>1$ indicate that aggregation is systematically related to $p$. Ordinary least squares regression was used to estimate the intercept and slope parameters using the REG procedure in SAS (version 9.2; SAS Institute, Cary, NC).

Covariance analysis was conducted on the data sets using the GENMOD procedure in SAS to determine the effect of sampling year (Year) on the slope and intercept parameters as described previously (8). Other factors such as cultivar and field age were not considered in the covariance analysis because of the relatively small number of data sets. To conduct the covariance analysis, the continuous variable $\ln [n \hat{p}(1-\hat{p})]$ was initially included in the model; then, Year was added individually as an intercept term and then as an interaction term with the slope. Year was considered significant if inclusion of this factor significantly $(P<0.05)$ reduced the sum of square error (SSE) compared with the null model without Year. Significance was determined by an $F$ test in which $F=$ (factor SSE/df factor $) /($ model SSE $/ d f$ model $)$ and $d f=$ degrees of freedom.

Correlation-based spatial analyses. Autocorrelation. First- and second-order autocorrelation statistics were calculated to quantify the degree of similarity of disease incidence between sampling units along a transect. Before autocorrelation coefficients were calculated, the data were transformed using the Haldane transformation $[\ln (y /(1-y)]$, where $y=(x+0.5) /(n+1)$ and $x$ is the number of diseased flowers in a sampling unit. This transformation avoids taking the logarithm of 0 values or dividing by 0 . Autocorrelation analyses were performed in Minitab (version 15; Minitab Inc., State College, PA).

Runs analyses. Ordinary and median runs analyses also were performed to characterize larger-scale patterns of diseased flowers among sampling units in a transect (17). For ordinary runs analysis, a sampling unit was assigned a value of 1 if at least one diseased flower was observed in the sampling unit and 0 otherwise. In median runs analysis, the median incidence of disease was calculated for each data set. Sampling units were then coded as 1 or 0 if the incidence of diseased flowers was above or below the median for that data set, respectively. A run was defined as a succession of one or more flowers with similar disease status (nondiseased or diseased). Runs and associated tests of significance (17) were calculated in Microsoft Excel (Microsoft Corp., Redmond, WA).

Cross-correlation analysis. The spatial association of apothecia to the incidence of diseased flowers in a sampling unit was quantified by Spearman's rank crosscorrelation. Spearman's rank crosscorrelation coefficient (denoted by $\hat{\rho}_{k}$ ) provides a measure of the association between variables separated by a lag distance, $k$. Because discrete values for apothecia counts and binary incidence values violate the normality assumptions for parametric cross-correlation analysis, Spearman's nonparametric rank correlation was used for these analyses (26). Values of $\hat{\rho}_{k}$ may range from -1 to 1 , where the sign indicates a positive or negative association between variables and the strength of a relationship is proportional to the magnitude of the statistic. For example, if two variables are positively associated at a specified lag distance, then large ranks of each variable will occur together and $\hat{\rho}_{k}$ will be positive. Turechek and Madden (27) provide a thorough explanation of the test. Correlations were calculated between all pairs of variables separated by lag $(k)$ distances of -5 to 5 sampling units, including 0 (the same sampling unit). In total, 55 data sets were used in this analysis because no apothecia were observed in nine of them and, hence, were noninformative. Average values were used when there were ties in ranks. Rank transformation and cross-correlation coefficients were calculated in Minitab (version 15; Minitab Inc.).

\section{RESULTS}

Disease incidence. Sclerotinia flower blight was found in all fields assessed and incidence ranged from 0.01 to 0.43 among all 64 transects (data sets), with a mean of 0.18 and median of 0.19 . Disease incidence increased over time in all fields (Fig. 2 ). The average isolation frequency of $S$. sclerotiorum from diseased flowers sampled within fields $\mathrm{A}, \mathrm{C}$, and $\mathrm{E}$ was $80 \%$. Moreover, no B. cinerea was found within these samples.

Temporal analysis. The incidence of Sclerotinia flower blight over time was best described by the monomolecular model in 11 of the 12 transects, whereas the remaining transect was best explained by a logistic model (Table 1). In fields where epidemics were best fit to the monomolecular model, this explained at least $84.8 \%$ of the variation in the incidence of Sclerotinia flower blight. The rates of disease progress were considered slow, ranging from 0.002 to 0.023 units per day among the fields (Table 1).

Emergence of apothecia appeared to be well synchronized with flower development (Fig. 2). During the autumn period following harvest, apothecial density was $0.2 \mathrm{~m}^{-1}$ or less in all fields surveyed. Averaged over all fields and years, there was a clear relationship between the number of apothecia per meter and the incidence of diseased flowers (Fig. 3A). The strength of the association was $S=0.88(P<0.0001)$. The number of apothecia also was closely related to the days after initiation of disease assessments $(S=0.85 ; P<0.0001$;

Table 1. Temporal disease progress models and associated summary statistics for the fit of the incidence of Sclerotinia flower blight in five pyrethrum fields in Tasmania, Australia

\begin{tabular}{|c|c|c|c|c|c|c|c|c|}
\hline$\overline{\text { Year }}$ & Field (transect) & Model of best fit ${ }^{a}$ & $P$ & Slope & Intercept & $R^{* 2 \mathrm{~b}}$ & RMSE $^{\mathbf{c}}$ & $\mathrm{CV}(\%)^{\mathrm{d}}$ \\
\hline \multirow[t]{4}{*}{2007} & A (1) & Monomolecular & 0.016 & 0.019 & -6.504 & 0.882 & 0.049 & 21.52 \\
\hline & A (2) & Monomolecular & 0.026 & 0.023 & -7.694 & 0.798 & 0.074 & 29.76 \\
\hline & $\mathrm{C}(1)$ & Monomolecular & 0.003 & 0.010 & -3.410 & 0.948 & 0.019 & 12.52 \\
\hline & $\mathrm{C}(2)$ & Monomolecular & $<0.001$ & 0.009 & -3.106 & 0.992 & 0.007 & 4.12 \\
\hline \multirow[t]{2}{*}{2008} & B (1) & Monomolecular & 0.002 & 0.007 & -2.044 & 0.917 & 0.039 & 16.49 \\
\hline & B (2) & Monomolecular & 0.007 & 0.002 & -2.068 & 0.912 & 0.026 & 9.73 \\
\hline \multirow[t]{6}{*}{2009} & $\mathrm{D}(1)$ & Monomolecular & $<0.001$ & 0.007 & -2.098 & 0.985 & 0.009 & 4.80 \\
\hline & $\mathrm{D}(2)$ & Monomolecular & 0.002 & 0.008 & -2.578 & 0.959 & 0.019 & 8.89 \\
\hline & E (1) & Monomolecular & 0.038 & 0.006 & -2.033 & 0.743 & 0.037 & 29.80 \\
\hline & $\mathrm{E}(2)$ & Monomolecular & 0.0006 & 0.008 & -2.780 & 0.984 & 0.012 & 9.24 \\
\hline & $F(1)$ & Monomolecular & 0.0007 & 0.009 & -2.997 & 0.982 & 0.013 & 8.34 \\
\hline & $F(2)$ & Logistic & 0.0114 & 0.0082 & -30.253 & 0.883 & 0.038 & 26.41 \\
\hline
\end{tabular}

${ }^{a}$ Model of best fit selected by fitting the linear, monomolecular, exponential, logistic, and Gompertz models using nonlinear regression and examination of the linear forms of each model. Further evidence for selection was gained by data back-transformation and comparison of the coefficient of determinations.

${ }^{\mathrm{b}}$ Back-transformed $R^{* 2}$.

${ }^{\mathrm{c}}$ Root mean square error.

${ }^{d}$ Coefficient of variation. 
Fig. 3B), indicating an association between apothecial density and flower maturity.

Point pattern analyses. Distributional analyses. Spatial analyses at the scale of the sampling unit indicated that disease incidence was highly aggregated, particularly when disease incidence was greater than 0.05 (Table 2). The log likelihood ratio test was significant for $92 \%$ of the data sets, indicating that the $\beta$-binomial distribution provided a better fit to the data than the binomial (random) distribution. Similarly, the $C(\alpha)$ test indicated that the $\beta$-binomial distribution provided a better fit than the binomial distribution for $95 \%$ of data sets. The frequency distribution of the heterogeneity parameter $\hat{\theta}$ was rightskewed and ranged from 0 to 0.75 , with a mean of 0.13 and median of 0.16 among all fields surveyed, indicating a relatively low degree of aggregation (Fig. 4B; Table $2)$. The parameter value tended to increase with disease incidence up to $\hat{p}=0.5$, as expected (12). The frequency distribution of the index of dispersion, $D$, also was right-skewed, ranging from 1.04 to 20.39 , with a mean of 6.17 and median of 5.58 (Fig. 4C). In $97 \%$ of data sets, $D$ was greater than 1 , indicating aggregation.

Binary power law analyses. The binary power law provided a good fit to the data with coefficients of determination $\left(R^{2}\right)$ of at least 0.90 for all years (Fig. 5; Table 3). When calculated over all years, estimates of the slope and intercept parameters were 1.63 and 0.68 , respectively. The $95 \%$ confidence intervals for the slope and intercept parameter estimates were greater than and did not include 1 and 0 , respectively, indicating that the incidence of diseased flowers was highly aggregated and the degree of heterogeneity changed systematically with $p$ in all years. However, covariance analysis indicated that slope and intercept parameter estimates differed between years $(P<0.0001$; Table 4). In 2008, the intercept was not significantly different from 0 ( $t=1.24 ; P=0.24)$ but, in all other years, the intercept and slope were greater than 0 and 1 , respectively.

Correlation-based spatial analyses. Autocorrelation. Significant first-order autocorrelation, $\hat{r}_{1}$, was detected in $69 \%$ of the data sets, with significant second-order autocorrelation in $9 \%$ of data sets (Table 2). The frequency distribution of $\hat{r}_{1}$ ranged from -0.39 to 0.72 and was left-skewed, with a mean of 0.37 and median of 0.41 (Fig. 4D), with a general tendency for $\hat{r}_{1}$ to increase with $\hat{p}$ up to values of 0.1 to 0.2 . At lag $=2$, mean $\hat{r}_{2}$ was 0.09 , with a median of 0.06 , suggesting that significant aggregation was mostly at the scale of neighboring sampling units.

Runs analyses. Significant $(P<0.05)$ aggregation was detected in only $38 \%$ of the data sets by median runs analysis and $34 \%$ of the data sets where ordinary runs could be used (Table 2). Among the disease-incidence classes evaluated, there was a general tendency for median runs analyses to detect aggregation in a greater proportion of data sets as $\hat{p}$ increased, which was also apparent by visual inspection of scatter plots of $\hat{p}$ and the standard-normal $Z$ statistic (data not presented). A relation- ship between $\hat{p}$ and the standard-normal $Z$ statistic for ordinary runs was not apparent (data not presented).

Cross-correlation analysis. The strongest median value of correlation between the number of apothecia and disease inci-
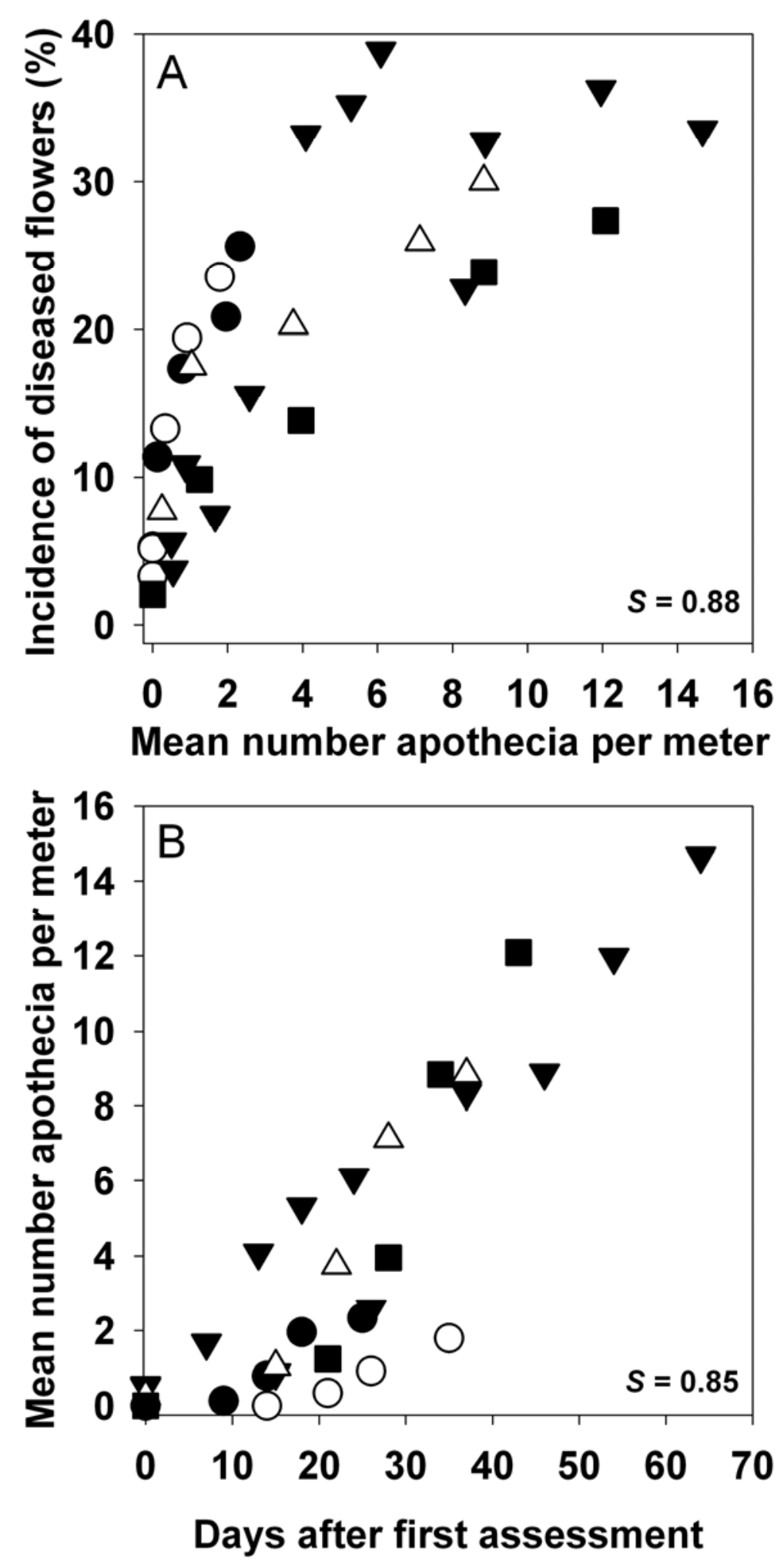

Fig. 3. Relationship between the number of apothecia of Sclerotinia sclerotiorum and $\mathbf{A}$, the incidence of flowers with Sclerotinia flower blight and $\mathbf{B}$, the days after the first disease assessment in six pyrethrum fields in Tasmania, Australia. Each field is represented by a different symbol and is the mean of 50 samplings units collected from two transects. The magnitude of Spearman's rank correlation coefficient $(S)$ is presented numerically on each graph $(P<0.0001$ in both cases $)$. 
dence occurred at a lag of $k=0$ (Fig. 6A), meaning when apothecia and disease were assessed in the same sampling unit. At this scale, the value of $\hat{\rho}_{0}$ ranged from -0.52 to 0.72 , with a median of 0.19 (Fig. 6B), and significant correlations were detected in $27 \%$ of the 55 data sets where $\hat{\rho}_{0}$ could be calculated. At lags ranging from $k=-2$ to 2 , significant correlations were detected in 9 to $13 \%$ of the data sets, with a corresponding median $\hat{\rho}_{k}$ of -0.01 to 0.12 , indicating a low degree of correlation at these scales. Spatial correlations between apothecia and disease incidence decreased markedly when correlations were made at sampling units separated by more than two lags (Fig. 6A), and the proportion of significant correlations was similar to the type I error rate of the statistic $(\alpha=0.05)$.

\section{DISCUSSION}

This study has developed quantitative information on the spatiotemporal characteristics of Sclerotinia flower blight epidemics in Australian pyrethrum fields. Disease incidence and rates of disease progress were generally low, with maximum disease incidence across all fields of $43 \%$. Temporal dynamics of the epidemics were best described by the monomolecular model, indicative of a monocyclic epidemic (16). This inferred one extended cycle of infection over the flowering period. Interestingly, the number of apothecia per meter was highly correlated with disease incidence, the number of flowers produced on each stem (data not presented), and the days since the disease assessment began. The latter phenomenon indicates synchronous development between carpogenic germination of S. sclerotiorum and availability of host tissue for infection (i.e., pyrethrum flowers). This phenomenon has also been described in other hosts $(1,2)$. The apparent synchronization of apothecia emergence and flower development is particularly striking given the generally wide range of environmental factors affecting carpogenic germination, the most important being temperature and water potential $(6,7,24)$. Optimum reported temperature ranges for carpogenic germination of S. sclerotiorum vary but are generally between 10 and $20^{\circ} \mathrm{C}(1,11)$. These temperature ranges are typical of those experienced in the pyrethrum production district during the flowering period, indicating that weather factors alone may not be responsible for the linear increase in apothecia numbers over time. The number of apothecia found per meter was extraordinarily high, in some fields reaching over 14 per meter by the final assessment. Negligible numbers of apothecia ( 1 or 0 per transect) were found during assessments conducted throughout the subsequent autumn periods when plants were in a rosette form.

Collectively, spatial analyses indicated a high degree of aggregation of disease incidence at the scale of individual sampling
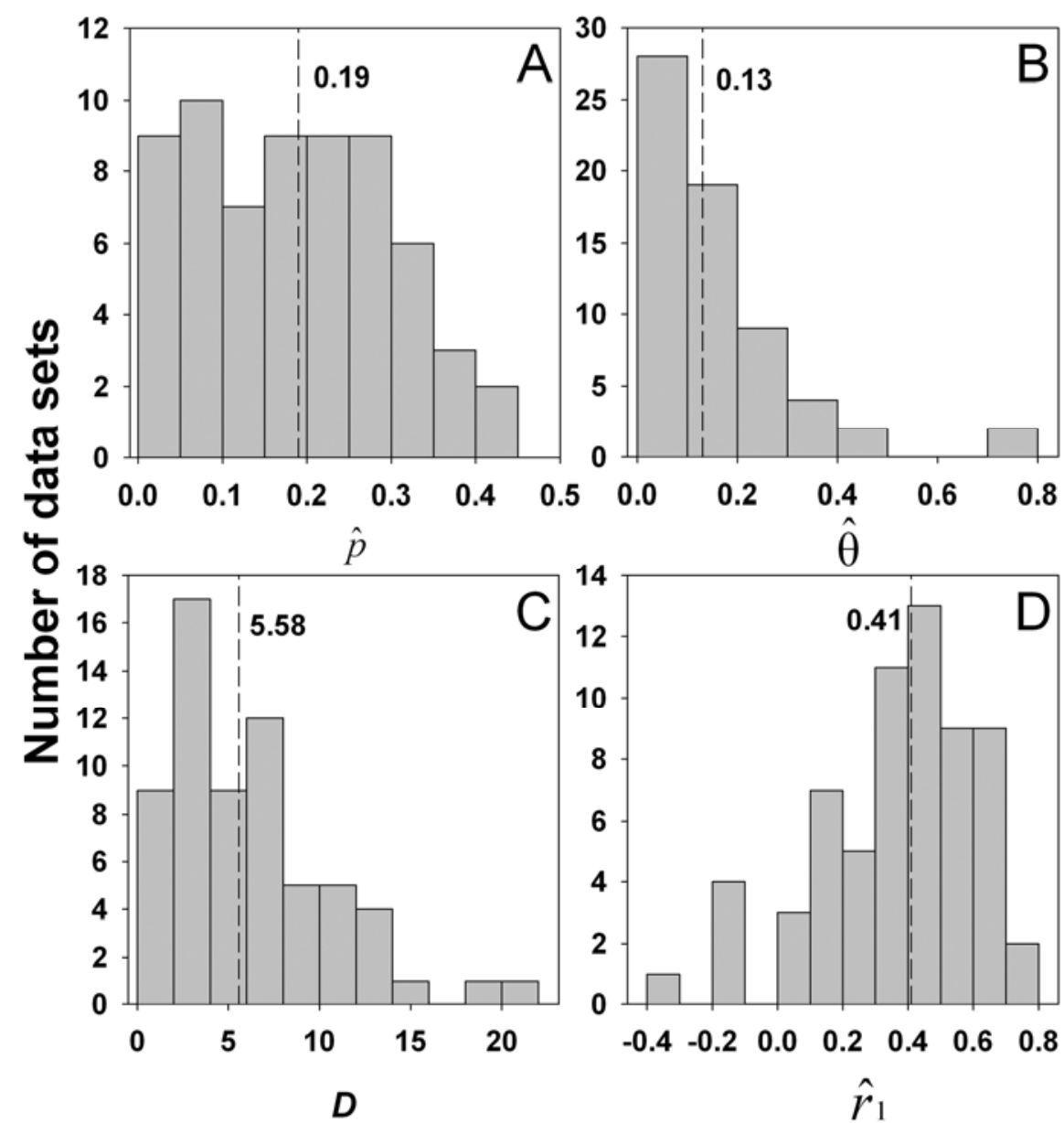

Fig. 4. Frequency distribution of the $\beta$-binomial distribution parameters $\mathbf{A}, \hat{p}$ and $\mathbf{B}, \hat{\theta} ; \mathbf{C}$, the index of dispersion $D$; and $\mathbf{D}$, the first-order autocorrelation statistic $\hat{r}_{1}$ for the incidence of Sclerotinia flower blight as assessed in 64 transects in six pyrethrum fields in Tasmania, Australia. Vertical dashed lines are the median value for the indicated statistic, with the numerical value given on each graph.

Table 2. Tests of aggregation and spatial pattern of the incidence of Sclerotinia flower blight from pyrethrum fields in Tasmania, Australia from 2007 to 2009

\begin{tabular}{|c|c|c|c|c|c|c|c|c|c|}
\hline \multirow[b]{2}{*}{ Incidence $^{d}$} & \multirow[b]{2}{*}{$T^{\mathrm{e}}$} & \multirow[b]{2}{*}{ LRS $^{f}$} & \multicolumn{2}{|c|}{ Variance tests $^{\mathbf{a}}$} & \multicolumn{3}{|c|}{ Median values $^{\mathbf{b}}$} & \multicolumn{2}{|c|}{ Runs analysis $^{c}$} \\
\hline & & & $C(\alpha)$ & $D$ & $\hat{\theta}$ & $D$ & $\hat{r}$ & Median & Ordinary \\
\hline 0 & 0 & $\ldots$ & .. & $\ldots$ & $\ldots$ & $\ldots$ & $\ldots$ & $\ldots$ & .. \\
\hline $0.00-0.05$ & 9 & 0.56 & 0.78 & 0.78 & 0.03 & 1.71 & 0.14 & 0.22 & 0.22 \\
\hline $0.05-0.10$ & 10 & 0.90 & 0.90 & 1.00 & 0.08 & 2.68 & 0.36 & 0.40 & 0.40 \\
\hline $0.10-0.20$ & 16 & 1.00 & 1.00 & 1.00 & 0.09 & 4.09 & 0.48 & 0.44 & 0.38 \\
\hline $0.20-0.40$ & 27 & 1.00 & 1.00 & 1.00 & 0.19 & 7.62 & 0.45 & 0.37 & 0.37 \\
\hline$>0.40$ & 2 & 1.00 & 1.00 & 1.00 & 0.73 & 19.63 & 0.34 & 0.50 & 0.00 \\
\hline All & 64 & 0.92 & 0.95 & 0.97 & 0.13 & 5.58 & 0.41 & 0.38 & 0.34 \\
\hline
\end{tabular}

${ }^{\text {a }}$ Proportion of data sets in which the $C(\alpha)\left(Z\right.$ statistic) or $D\left(\chi^{2}\right)$ tests were significant $(P \leq 0.05)$.

${ }^{\mathrm{b}}$ Median estimated value of the $\beta$-binomial distribution parameter $\hat{\theta}$, index of dispersion, $D$, and first-order autocorrelation statistic, $\hat{r}$.

${ }^{c}$ Percentage of data sets in which runs analysis indicated significant aggregation. Ordinary runs analysis was based on 21 or 1 data sets in disease incidence classes 0.20 to 0.40 and $>0.40$, respectively, because runs could not be calculated when all sampling units had at least one diseased flower

${ }^{\mathrm{d}}$ Incidence of pyrethrum flowers with Sclerotinia flower blight. Disease incidence class ends with the indicated value. Classes start with the next highest value above the listed value.

${ }^{\mathrm{e}}$ Number of data sets in each disease incidence class.

${ }^{\mathrm{f}}$ Proportion of data sets in which the likelihood ratio test statistic was significant $(P \leq 0.05)$. 
units, with some patches of similar disease status extending beyond the borders of sampling units to 1 to $1.5 \mathrm{~m}$. Crosscorrelations analysis indicated that the of apothecia and disease incidence occurred when apothecia and disease were assessed in the same or neighboring sampling units. Taken together with the results of the temporal analysis, the current study suggests a localized relationship between apothecia presence and flower blight development, with apparently limited escape and dispersal of ascospores from the pyrestrongest association between the number

thrum canopy. Significant spatial associations between diseased flowers and apothecia have also been characterized in other hosts, such as soybean (4), and are indicative of very local spread of ascospores from the apothecial inoculums under the dense pyrethrum canopy. Therefore, it is intuitive that a limited proportion of the ascospore population released from apothecia at the soil line underneath the canopy would be able to escape and cause flower infection. Moreover, little evidence was found of a contribution from "background" (herein defined as outside of the

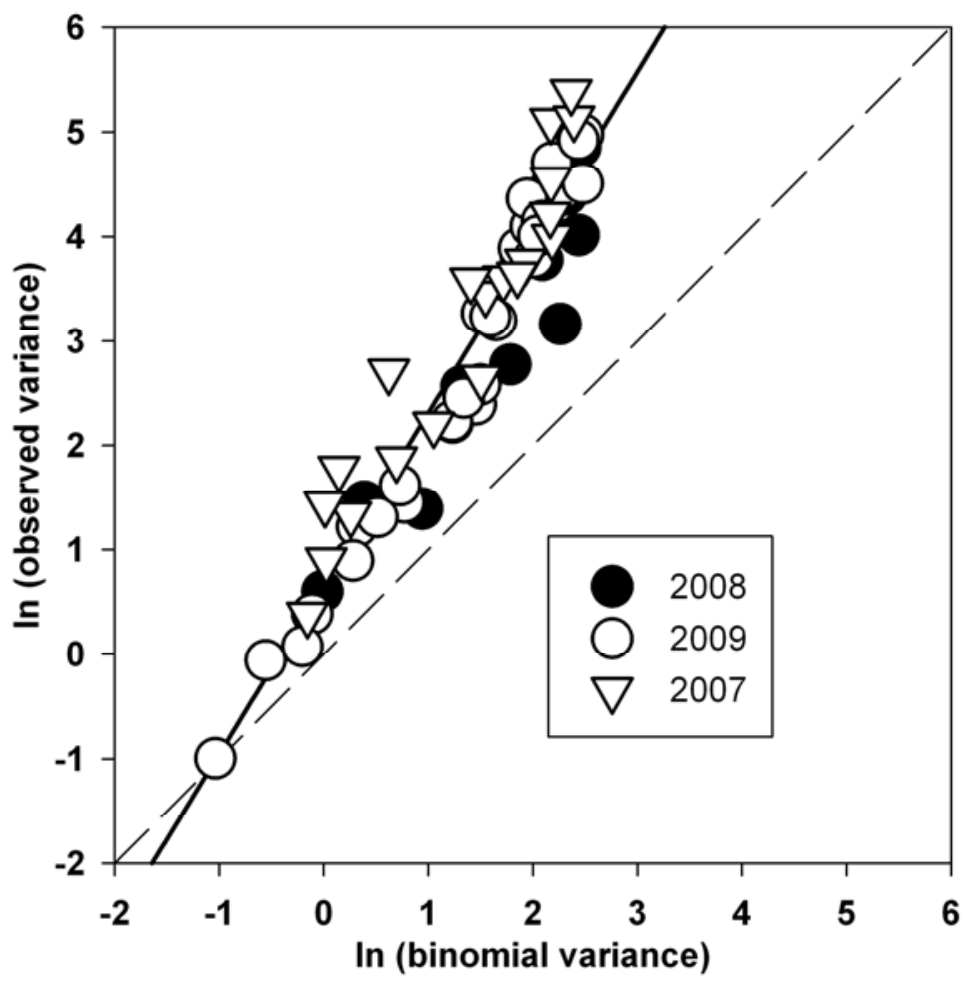

Fig. 5. Relationship between the logarithms of the observed variance and binomial variance of the incidence of Sclerotinia flower flight in pyrethrum fields in Tasmania, Australia. The solid line is the least squares regression fit to all 3 years and the dashed line represents for a binomial (random) distribution of disease incidence. Slope and intercept parameter estimates are given in Table 3.

Table 3. Estimated intercept $\left(\ln \left[\hat{A}_{x}\right]\right)$ and slope $(\hat{b})$ parameters of the binary power law fit to the incidence of Sclerotinia flower blight in pyrethrum fields in Tasmania, Australia ${ }^{\mathrm{a}}$

\begin{tabular}{llccc}
\hline Year & $\boldsymbol{d} \boldsymbol{f}$ & $\hat{b}(\mathbf{S E})$ & $\boldsymbol{\operatorname { l n }}\left(\hat{A}_{\boldsymbol{x}}\right)(\mathbf{S E})$ & $\boldsymbol{R}^{\mathbf{2}}$ \\
\hline 2007 & 18 & $1.584(0.114)$ & $1.017(0.178)$ & 0.92 \\
2008 & 12 & $1.641(0.160)$ & $0.381(0.307)$ & 0.90 \\
2009 & 28 & $1.722(0.054)$ & $0.500(0.089)$ & 0.97 \\
All & 62 & $1.631(0.059)$ & $0.678(0.099)$ & 0.92 \\
\hline
\end{tabular}

${ }^{\mathrm{a}} d f=$ Degrees of freedom for regression and $\mathrm{SE}=$ standard error of the mean. transect study area of interest) ascospore inoculum. Translated into a within-field scale, this would indicate that diseased flowers are more likely to be found in those areas where apothecia are produced, and inoculum transfer between adjacent fields or longer distances may be limited.

Current management strategies for Sclerotinia flower blight in pyrethrum include a prophylactic approach to fungicide applications, regardless of the presence and density of inoculum. Therefore, improvements to disease management strategies should be directed toward reducing the level of initial inoculum or predicting those sites which may be predisposed to being at higher risk. Forecasting systems for diseases in other production systems caused by $S$. sclerotiorum by predicting carpogenic germination have involved a risk-point table system (28) and thermaltime analysis (6). The latter study recommended that prediction could be improved by incorporating functions describing fluctuating soil moisture conditions (6), which are typical of overhead irrigation applied during the flowering period of pyrethrum in early summer. Agronomic strategies that reduce $S$. sclerotiorum sclerotial inoculum include extended rotation periods with a nonhost species (5). However, this is difficult to achieve when many of the crop plants in the pyrethrum rotation (e.g., carrot, bean, and potato) are also excellent hosts of S. sclerotiorum. Tillage has been found to reduce carpogenic germination with variable results. For example, Williams and Stelfox (30) reported a reduction in sclerotial populations from deep plowing but, in contrast, fewer apothecia have been also associated with no-tillage systems (9). The effect of fertilizer on the number of apothecia has also been contradictory $(7,25)$, and is likely to be site and fertilizer specific. From a disease incidence perspective, agronomic practices that enhance yield, such as increasing plant density, are also likely to promote carpogenic germination, flower infection, and subsequent disease development. In contrast, for another important disease of pyrethrum, ray blight caused by Phoma ligulicola var. inoxydablis, studies have shown that, when plant density is reduced by half that of the industry standard, flower survival can be significantly increased without significant reductions in pyrethrin yield (23).

Table 4. Covariance analysis of the effect of the year of sampling (Year) on the intercept $\left(\ln \left[\hat{A}_{x}\right]\right)$ and slope $(\hat{b})$ parameters of the binary power law for the incidence of Sclerotinia flower blight in pyrethrum fields in Tasmania, Australia ${ }^{\mathrm{a}}$

\begin{tabular}{|c|c|c|c|c|c|c|c|c|c|c|}
\hline \multirow[b]{2}{*}{ Factor } & \multirow[b]{2}{*}{$d f$ SSE } & \multirow[b]{2}{*}{$d f$ Factor } & \multicolumn{4}{|c|}{$\ln \left(\hat{A}_{x}\right)$} & \multicolumn{4}{|c|}{$\hat{b}$} \\
\hline & & & SSE & Diff. & $F$ & $P$ & SSE & Diff. & $F$ & $P$ \\
\hline Null model & 62 & $\ldots$ & 11.441 & & & & 11.441 & & & \\
\hline Year & 60 & 2 & 8.644 & 2.798 & 9.709 & 0.000 & 9.680 & 1.761 & 5.457 & 0.007 \\
\hline
\end{tabular}

${ }^{a} d f$ SSE $=$ degrees of freedom for the model sum of squares error (SSE); $d f$ factor = degrees of freedom for factor; Diff. = difference between the SSE of the binary power law model versus the binary power law model with year included in the analysis; and $F=$ significance level for the difference between SSE of the binary power law model versus binary power law model with year as determined by an $F$ test, where $F=$ (factor SSE/df factor)/(model SSE/df model). 
These results will allow for the development of testable hypotheses on the relative contributions of inoculum to the spatial patterns of Sclerotinia flower blight, and to make inferences concerning the most appropriate management options based on the temporal disease progress of epidemics. Future research will aim at quantifying the losses caused by this disease, identifying the site-specific risk factors affecting disease development, and an assessment of whether this information can
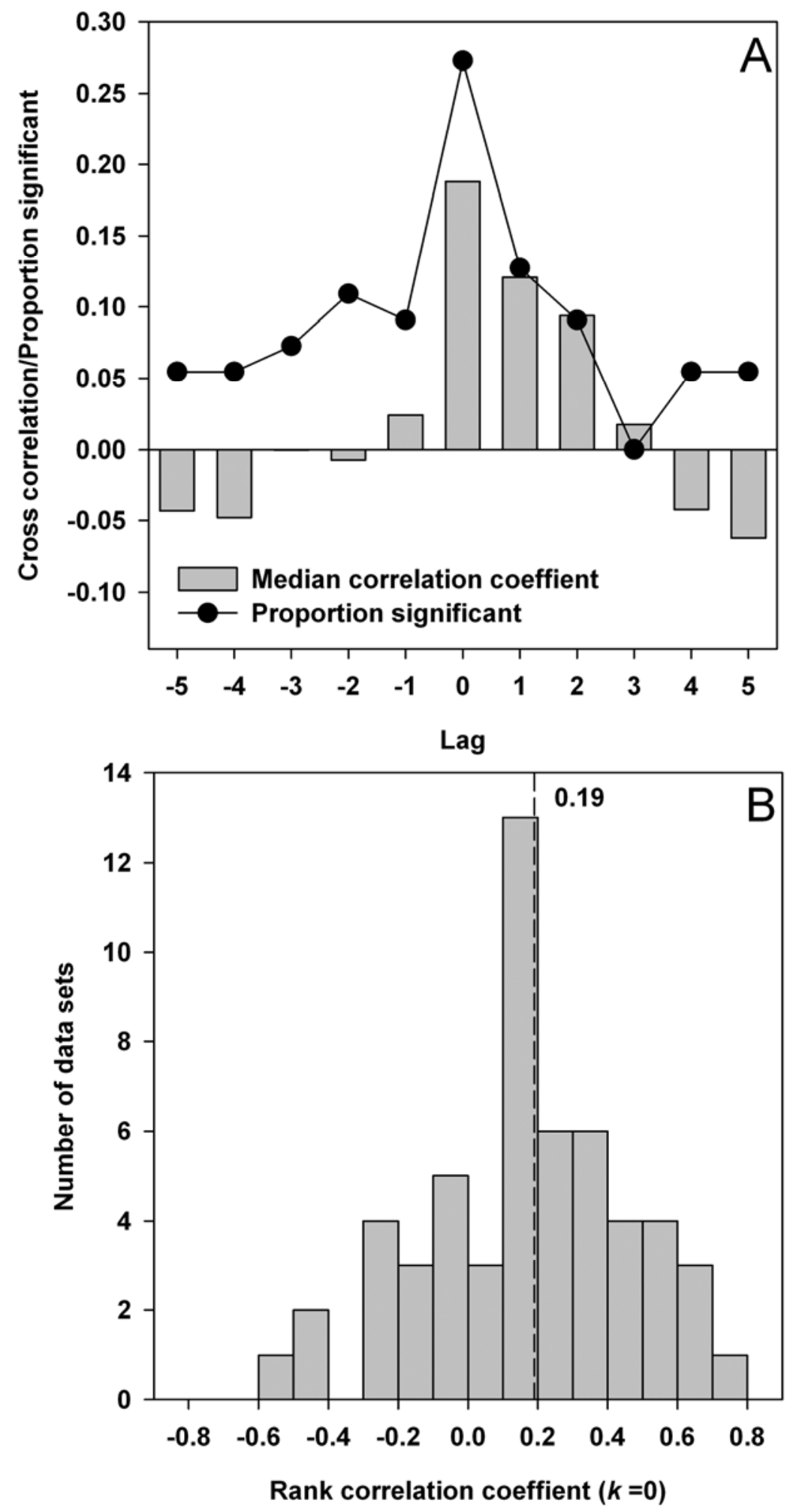

Fig. 6. A, Median value of the rank cross-correlation coefficient of the association between the number of apothecia per meter and the incidence of Sclerotinia flower blight in pyrethrum fields in Tasmania, Australia. Statistics were calculated from 55 data sets (transects) where both apothecia and Sclerotinia flower blight were present; 9 data sets where no apothecia were observed were excluded from the analysis. B, Frequency distribution of the rank cross-correlation coefficient at lag $(k)=0$. Median value is indicated by the dashed line and given numerically on the graph.

be combined into a predictive model to optimize fungicide usage. Describing the relationship between Sclerotinia flower blight and crown rot in subsequent seasons is also paramount for the design of these management strategies.

\section{ACKNOWLEDGMENTS}

We thank the financial supporters of our research and extension programs, including Botanical Resources Australia-Agricultural Services Pty. Ltd. (BRA), the OECD-Cooperative Research Program, France, Horticulture Australia, Ltd. (programs OT05002 and PY09002), and the United States Department of Agriculture-Agricultural Research Service CRIS 5358-21000-035-00; R. Arvier, M Raspin (BRA), and T. O'Malley (Tasmanian Institute of Agricultural Research, University of Tasmania) for their excellent technical assistance; and J. Scott and J. Woods for their helpful review of an earlier draft of this article.

\section{LITERATURE CITED}

1. Abawi, G. S., and Grogan, R. G. 1979. Epidemiology of diseases caused by Sclerotinia species. Phytopathology 69:899-904.

2. Abawi, G. S., Polach, F. J., and Molin, W. T. 1975. Infection of bean by ascospores of Whet zelinia sclerotiorum. Phytopathology 65:673678.

3. Bhat, B. K., and Menary, R. C. 1984. Pyrethrum production in Australia: its past and present potential. J. Aus. Inst. Agric. Sci. 189-192.

4. Boland, G. J., and Hall, R. 1988. Relationships between the spatial pattern and number of apothecia of Sclerotinia sclerotiorum and stem rot of soybean. Plant Pathol. 37:329-336.

5. Boland, G. J., and Hall, R. 1994. Index of plant hosts of Sclerotinia sclerotiorum. Can. J. Plant Pathol. 16:93-108.

6. Clarkson, J. P., Phelps, K., Whipps, J. M., Young, C. S., Smith, J. A., and Watling, M 2004. Forecasting Sclerotinia disease on lettuce: toward developing a prediction model for carpogenic germination of sclerotia. Phytopathology 94:268-279.

7. Ferraz, L. C., CaféFilho, A. C., Nasser, L. C. and Azevedo, J. 1999. Effects of soil moisture, organic matter and grass mulching on the carpogenic germination of sclerotia and infection of bean by Sclerotinia sclerotiorum. Plant Pathol. 48:77-82.

8. Gent, D. H., Turechek, W. W., and Mahaffee, W. F. 2008. Spatial and temporal stability of the parameters of the binary power law. Phytopathology 98:1107-1117.

9. Gracia-Garza, J. A., Boland, G. J., and Vyn, T. J. 2002. Influence of crop rotation and reduced tillage on white mold of soybean caused by Sclerotinia sclerotiorum. Can J. Plant Pathol. 24:115-121

10. Grdiša, M., Carović-Stanko, K., Kolak, I., and Šatović, Z. 2009. Morphological and biochemical diversity of Dalmatian pyrethrum (Tanacetum cinerariifolium (Trevir.) Sch. Bip.). Agric. Consp. Sci. 74:73-80.

11. Hao, J. J., Subbarao, K. V., and Duniway, J. M. 2003. Germination of Sclerotinia minor and $S$. sclerotiorum sclerotia under various soil moisture and temperature combinations. Phytopathology 93:443-450.

12. Hughes, G., and Madden, L. V. 1992. Aggregation and incidence of disease. Plant Pathol. 41:657-60.

13. MacDonald, W. L. 1995. Pyrethrum flowersproduction in Australia. Pages 55-66 in: Pyrethrum Flowers: Chemistry, Toxicology and Uses. J. E. Casida and G. B. Quistad, eds. Oxford University Press, New York

14. Madden, L. V., and Hughes, G. 1994. BBDcomputer software for fitting the beta-binomial 
distribution to disease incidence data. Plant Dis. 78:536-540.

15. Madden, L. V., and Hughes, G. 1995. Plant disease incidence: distributions, heterogeneity, and temporal analysis. Annu. Rev. Phytopathol. 33:529-564

16. Madden, L. V., Hughes, G., and van den Bosch, F. 2007. The Study of Plant Disease Epidemics. American Phytopathological Society, St. Paul, MN.

17. Madden, L. V., Louie, R., Abt, J. J., and Knoke, J. K. 1982. Evaluation of tests for randomness of infected plants. Phytopathology 72:195-198.

18. Natrass, R. M. 1950. Pyrethrum wilt in Kenya caused by Sclerotinia minor. East Afr. Agric. J. 16:53.

19. Neher, D. A., Reynolds, R. L., and Campbell, C. L. 1997. Analysis of disease progress curves using linear models. Pages 29-33 in: Exercises in Plant Disease Epidemiology. L. J. Francl and D. A. Neher, eds. The American Phytopathological Society, St. Paul, MN.

20. Nutter, F. W., Jr. 1997. Quantifying the tempo- ral dynamics of plant virus epidemics: a review. Crop Prot. 16:603-618.

21. Pethybridge, S. J., Hay, F. S., Esker, P. D., Gent, D. H., Wilson, C. R., and Nutter, F. W., Jr. 2008. Diseases of pyrethrum in Tasmania: challenges and prospects for management. Plant Dis. 92:1260-1272.

22. Pethybridge, S. J., Hay, F. S., Wilson, C. R., and Groom, T. 2005. Development of a fungicide-based management strategy for foliar disease caused by Phoma ligulicola in Tasmanian pyrethrum fields. Plant Dis. 89:1114-1120.

23. Pethybridge, S. J., Ngugi, H. K., and Hay, F. S. 2010. Use of survival analysis to assess management options for ray blight in Australian pyrethrum fields. Plant Pathol. 59:480-491.

24. Phillips, A. J. L. 1987. Carpogenic germination of sclerotia of Sclerotinia sclerotiorum: a review. Phytophylactica 19:279-283.

25. Schwartz, H. F., and Steadman, J. R. 1978. Factors affecting sclerotium populations of, and apothecium production by, Sclerotinia sclerotiorum. Phytopathology 68:383-388.

26. Turechek, W. W. 2004. Nonparametric tests in plant disease epidemiology: characterizing disease associations. Phytopathology 94:10181021.

27. Turechek, W. W., and Madden, L. V. 2000 Analysis of the association between the incidence of two spatially aggregated foliar diseases of strawberry. Phytopathology 90:157170.

28. Twengstrom, E., Sigvalid, R., Svensson, C. and Yuen, J. 1998. Forecasting Sclerotinia stem rot in spring sown oilseed rape. Crop Prot. 17:405-411.

29. Willetts, H. J., and Wong, J. A. L. 1980. The biology of Sclerotinia sclerotiorum, S. trifoliorum, and $S$. minor with emphasis on specific nomenclature. Bot. Rev. 46:101-165.

30. Williams, J. R., and Stelfox, D. 1980. Influencing of farming practices in Alberta on germination and apothecium production of sclerotia of Sclerotinia sclerotiorum. Can. J. Plant Pathol. 2:169-172.

31. Winney, R. 1979. Performance of pyrethroids as domestic insecticides. Pyrethrum Post 13:132-136. 